\title{
Prevention of Premature Ovulation by Administration of Gonadotropin Releasing Hormone Antagonist the day After Ovulation Triggering in Diminished Ovarian Reserve Patients
}

\section{Prevenção da ovulação prematura por meio da administração de antagonismo de liberação de gonadotropismo no dia seguinte à ovulação}

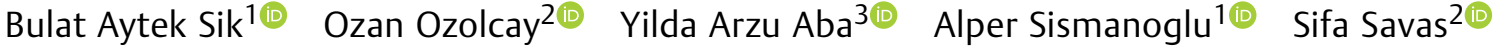 \\ Serkan Oral ${ }^{1}$ ()
}

${ }^{1}$ Department of Reproductive Endocrinology and Infertility, Sisli

Kolan International Hospital, Istanbul, Turkey

Address for correspondence Yilda Arzu ABA, Assoc. Prof., Bandirma

2 Department of Reproductive Endocrinology and Infertility, Istanbul Onyedi Eylül University, Faculty of Health Sciences, Balıkesir, Turkey

IVF Centre, Istanbul, Turkey

${ }^{3}$ Faculty of Health Sciences, Bandirma Onyedi Eylül University,

Balıkesir, Turkey

Rev Bras Ginecol Obstet 2022;44(3):245-250.

\section{Abstract \\ Keywords \\ - diminished ovarian reserve \\ - GnRH antagonist \\ - $\mathrm{M}_{2}$ oocyte \\ - premature ovulation \\ - pregnancy rates}

Objective The aim of the present retrospective study was to investigate the effectiveness of single-dose gonadotropin releasing hormone $(\mathrm{GnRH})$ antagonist administration, the day after human chorionic gonadotropin (hCG) triggering for final oocyte maturation, on the prevention of premature luteinization in patients with diminished ovarian reserve in in-vitro fertilization (IVF) cycles. The secondary objective of the study was to search the effect of this protocol on pregnancy outcomes.

Methods This is a retrospective study including 267 infertile patients who have single antral follicle seen with ultrasonography on the $2^{\text {nd }}$ or $3^{\text {rd }}$ day of the menstrual cycle before starting IVF treatment. We randomized patients into two groups. The case group comprised patients who had single-dose GnRH antagonist injection the day after hCG triggering formed, and the patients who had the standard treatment regime formed the control group. In both groups, the oocytes were collected 36 hours after hCG injection.

Results The premature ovulation rate was significantly low in the case group compared with the control group (6.86 versus $20.6 \%$ per scheduled cycle) $(p=0.022)$. Also, the oocyte retrieval rate (93.14 versus $67.87 \%$ per scheduled cycle) $(p=0.013)$, the oocyte maturity rate $(79.42$ versus $47.87 \%)(p=0.041)$, the fertilization rate $(65.68$ versus $34.54 \%)(p=0.018)$, and the embryo transfer rate per scheduled received

February 21, 2021

accepted

August 9, 2021

published online

February 9, 2022
DOI https://doi.org/

10.1055/s-0041-1736297. ISSN $0100-7203$. (c) 2022. Federação Brasileira de Ginecologia e Obstetrícia. All rights reserved.

This is an open access article published by Thieme under the terms of the Creative Commons Attribution License, permitting unrestricted use, distribution, and reproduction so long as the original work is properly cited. (https://creativecommons.org/licenses/by/4.0/)

Thieme Revinter Publicações Ltda., Rua do Matoso 170, Rio de Janeiro, RJ, CEP 20270-135, Brazil 


\section{Resumo}

\author{
Palavras-chave \\ - reserva ovariana \\ diminuída \\ - antagonista de \\ GnRH \\ - oócito M2 \\ - ovulação prematura \\ - taxas de gravidez
}

cycle (44.11 versus $18.78 \%)(p=0.003)$ were higher in the $\mathrm{GnRH}$ antagonist group than in the control group.

Conclusion The administration of GnRH antagonist the day after hCG trigger in IVF treatments of patients with diminished ovarian reserve enabled a significant decrease in the rate of premature ovulation but had no effect on live birth rate.

Objetivo O objetivo do presente estudo retrospectivo foi investigar a eficácia da administração do antagonista do hormônio liberador da gonadotrofina $(\mathrm{GnRH})$ em dose única no dia seguinte ao desencadeamento da gonadotrofina coriônica humana (hCG) para a maturação final do oócito, na prevenção da luteinização prematura em pacientes com diminuição do ovário reserva em ciclos de fertilização in vitro (FIV). $\mathrm{O}$ objetivo secundário do estudo foi pesquisar o efeito deste protocolo nos resultados da gravidez.

Métodos Trata-se de um estudo retrospectivo incluindo 267 pacientes inférteis que apresentam um único folículo antral visto por ultrassonografia no $2^{\circ}$ ou $3^{\circ}$ dia do ciclo menstrual antes de iniciar o tratamento de FIV. Nós randomizamos os pacientes em dois grupos. Os pacientes que receberam injeção de antagonista de GnRH em dose única no dia seguinte ao desencadeamento do hCG formaram o grupo caso, e os pacientes que receberam o regime de tratamento padrão formaram o grupo controle. Em ambos os grupos, os oócitos foram coletados 36 horas após a injeção de hCG.

Resultados A taxa de ovulação prematura foi significativamente baixa no grupo caso em comparação com o grupo controle (6,86 versus $20,6 \%$ por ciclo programado) $(p=0,022)$. Além disso, a taxa de recuperação de oócitos $(93,14$ versus $67,87 \%$ por ciclo programado) $(p=0,013)$, a taxa de maturidade do oócito $(79,42$ versus $47,87 \%)$ $(p=0,041)$, a taxa de fertilização $(65,68$ versus $34,54 \%)(p=0,018)$ e a taxa de transferência de embriões por ciclo programado $(44,11$ versus $18,78 \%)(p=0,003)$ foram maiores no grupo antagonista de $\mathrm{GnRH}$ do que no grupo controle.

Conclusão A administração de antagonista de $\mathrm{GnRH}$, no dia seguinte ao desencadeamento de hCG em tratamentos de FIV de pacientes com reserva ovariana diminuída permitiu uma redução significativa na taxa de ovulação precoce, mas não teve efeito na taxa de nascidos vivos.

\section{Introduction}

Early decrease is detected in the ovarian reserve in a mean of $10 \%$ of women due to various reasons regardless of age. Diminished ovarian reserve is determined in women with low antral follicle count and, therefore, with low response to ovarian stimulation and low fecundity compared with other women of their age despite having regular menstrual cycles. ${ }^{1}$ The increase of premature luteinization in patients with diminished ovarian reserve (particularly with a single oocyte) causes either cycle cancellation or early ovulation in the oocyte pick-up (OPU) period. ${ }^{2}$ Gonadotropin-releasing hormone $(\mathrm{GnRH})$ antagonists have recently been administered to avoid premature luteinizing hormone $(\mathrm{LH})$ increase, and luteinization in the controlled ovarian hyperstimulation $(\mathrm{COH})$ performed in in vitro fertilization (IVF) treatments. ${ }^{3}$ Gonadotropin releasing hormone $(\mathrm{GnRH})$ antagonists, particularly in comparison with the GnRH agonist protocols, decrease the LH fluctuations more safely and effectively, in a shorter period, with fewer injections, and with less adverse effects. ${ }^{4}$ Flare-up effect doesn't occur due to hypo estrogenic side effect, shorten the cycle period, decrease the amount of gonadotrophine dosage, immediate effect and directly binding to GnRH receptors in the pituitary gland were the most significant advantage of GnRH antagonist protocol. Also the suppression ofLH secretion happens in a short period of time. ${ }^{4,5}$ Although these advantages are also important for patients with normal ovarian reserve, they are more important in patients with diminished ovarian reserve. ${ }^{6}$

The aim of the present retrospective study was to analyze the effectiveness of single dose of GnRH antagonist injection 24 hours after hCG trigger in 267 infertile patients with only one antral follicle. The primary objective was to observe if this protocol decreases the premature ovulation, and the secondary goal was to search its effects on pregnancy results. 


\section{Methods}

This is a retrospective study including 267 infertile patients aged between 25 and 35 years old who were referred to the IVF Unit of the Istanbul IVF Center with the problem of infertility related to diminished ovarian reserve between January 2016 and May 2017, and who were detected as having a single antral follicle during the transvaginal ultrasonography (TVUSG) evaluation on the $2^{\text {nd }}$ or $3^{\text {rd }}$ day of their menstrual cycle. All the patients refused oocyte donation. Institutional Review Board approval was not required for the study due to its retrospective nature and to the fact that study data was constantly managed in a way that excluded the identification of subjects. Informed consent was obtained from all patients. Patients with male factor infertility, patients with $>1$ antral follicle, and patients $>35$ years old were excluded from the study. Fresh embryo transfer was performed to all the patients in the study.

Folliculometric measurement was performed with TVUSG on the $2^{\text {nd }}$ or $3^{\text {rd }}$ day of the menstrual cycle of 267 patients in the case and control groups. The treatment was initiated with $2.5 \mathrm{mg}$ oral letrozole administration (Femara tablet, Novartis, Italy) twice daily for 5 days. Controlled ovarian hyperstimulation was initiated with human menopausal gonadotropin (hMG) injection $150 \mathrm{IU} /$ day (Menopur $75 \mathrm{IU}$ SC/IM, Ferring, USA). Cetrorelix $0.25 \mathrm{mg}$ injection (GnRH antagonist) (Cetrotide $0.25 \mathrm{mg}$, Merck, Greece) was added to the regime when the follicle diameter was $\geq 12 \mathrm{~mm}$. The patients were monitored with TVUSG on alternate days until the follicle diameter reached between 18 and $19 \mathrm{~mm}$. When the follicle diameter was between 18 and $19 \mathrm{~mm}$, ovulation triggering was done with 5,000 units of IM/SC hCG (Choriomon $5000 \mathrm{IU}$, IBSA, Italy) injection and oocyte pickup was arranged 36 hours after hCG injection. A total of 102 patients, who were selected using the systematic randomization method, were administered a single dose of GnRH antagonist the day after hCG administration, and these patients constituted the case group. The control group included 165 patients who were administered the standard treatment regime with hCG trigger. The oocyte pickup procedure was performed by a single physician using a $17-G$ fine oocyte aspiration needle (Cook Medical, Brisbane, Australia) with TVUSG guidance and under sedative anesthesia. The egg retrieval time was 36 hours after hCG administration for the patients in both groups.

The obtained oocytes were separated with the denudation procedure using hyalarunidase (Life Global, Canada) from their surrounding cumulus 2 hours after collection. Intracytoplasmic sperm injection (ICSI) was performed to mature oocytes (metaphase II) after denudation. Normally fertilized zygotes, which were observed as 2PN (pronucleus) appearance 24 hours after ICSI, were cultured for 3 days in the culture medium (Life Global, Canada). All embryos were cultured in multigas incubators (Hessen, Almanya) at $37^{\circ} \mathrm{C}$, which provided the environment of $6 \% \mathrm{CO}_{2}$ and $5 \% \mathrm{O}_{2}$. On day 3 , fresh embryo transfer was performed to all the patients in the study. Embryo transfer was completed with the exact placement of the embryo transvaginally to the mid-uterus by a single physician under TVUSG guidance. Luteal phase support was initiated in all patients after embryo transfer.

The rates of premature ovulation and fresh embryo transfer are the indicators evaluated in the first phase for each cycle. The indicators evaluated in the second phase are clinical pregnancy rate and live birth rate per embryo transfer. Clinical pregnancy was described as positive with the detection of a gestational sac on the $6^{\text {th }}$ week of pregnancy using TVUSG. Pregnancy loss before the $22^{\text {nd }}$ week of pregnancy was described as missed abortion. The treatment process of the patients is shown in the flow diagram in - Fig. 1.

\section{Statistical Analysis}

SPSS for Windows version 11.0 (SPSS Inc., Chicago, IL, USA) was used for the statistical analysis of the present study. The Student $t$-test, the Mann-Whitney $U$ test, the paired $t$-test, the Wilcoxon rank test, the Fisher exact test, and the chisquared test were used for comparisons. Statistical significance was set at $p<0.05$. The association between $\mathrm{GnRH}$ antagonist administration and premature ovulation rate and the rate of embryo transfer per scheduled cycle was evaluated (adjusted for patient age, oestradiol concentration and follicular size on triggering day, and time interval between triggering and oocyte retrieval time).

\section{Results}

The results of 102 patients (38.2\%) in the study group who were administered single-dose GnRH antagonist the day after hCG administration, and those of 165 patients (61.8\%) who were administered standard treatment were compared; the results of the IVF cycles are summarized in - Table 1.

A statistically significant decrease in the premature ovulation rate (6.86 versus $20.6 \%$ per scheduled cycle) $(p=0.022)$ and a significant increase in the oocyte retrieval rate (93.14 versus $67.87 \%$ per scheduled cycle) $(p=0.013)$ were observed in the case group compared with the control group. In addition, a higher number of mature oocytes (79.42 versus $47.87 \%)(p=0.041)$ and fertilized (2PN) oocytes (65.68 versus $34.54 \%)(p=0.018)$ were obtained in the case group. A higher number of embryo transfers could be performed in the case group (44.11 versus $18.78 \%)(p=0.003)$. However, no significant difference was detected between the case and control groups regarding the rates of clinical pregnancies and live births $(p>0.05)$.

There were no statistically significant differences between the case and control groups regarding estradiol levels $(178 \pm 58.2 \mathrm{IU} / \mathrm{ml}$ versus $174 \pm 67.3 \mathrm{IU} / \mathrm{ml})(p=0.6082)$ and LH levels $(4.6 \pm 0.7 \mathrm{IU} / \mathrm{ml}$ versus $4,9 \pm 0.9 \mathrm{IU} / \mathrm{ml})(p=0.510)$ measured on the day of ovulation triggering. In addition, no difference was observed in gestational age at delivery $(37.6 \pm 1.5$ versus $37.9 \pm 1.3$ weeks) and birthweight of singleton newborns $(2,786 \pm 417$ versus $2,893 \pm 510$ grams $)$ between both groups.

\section{Discussion}

During IVF treatments with GnRH antagonist protocols, all of us sometimes observe premature increase in LH levels before 


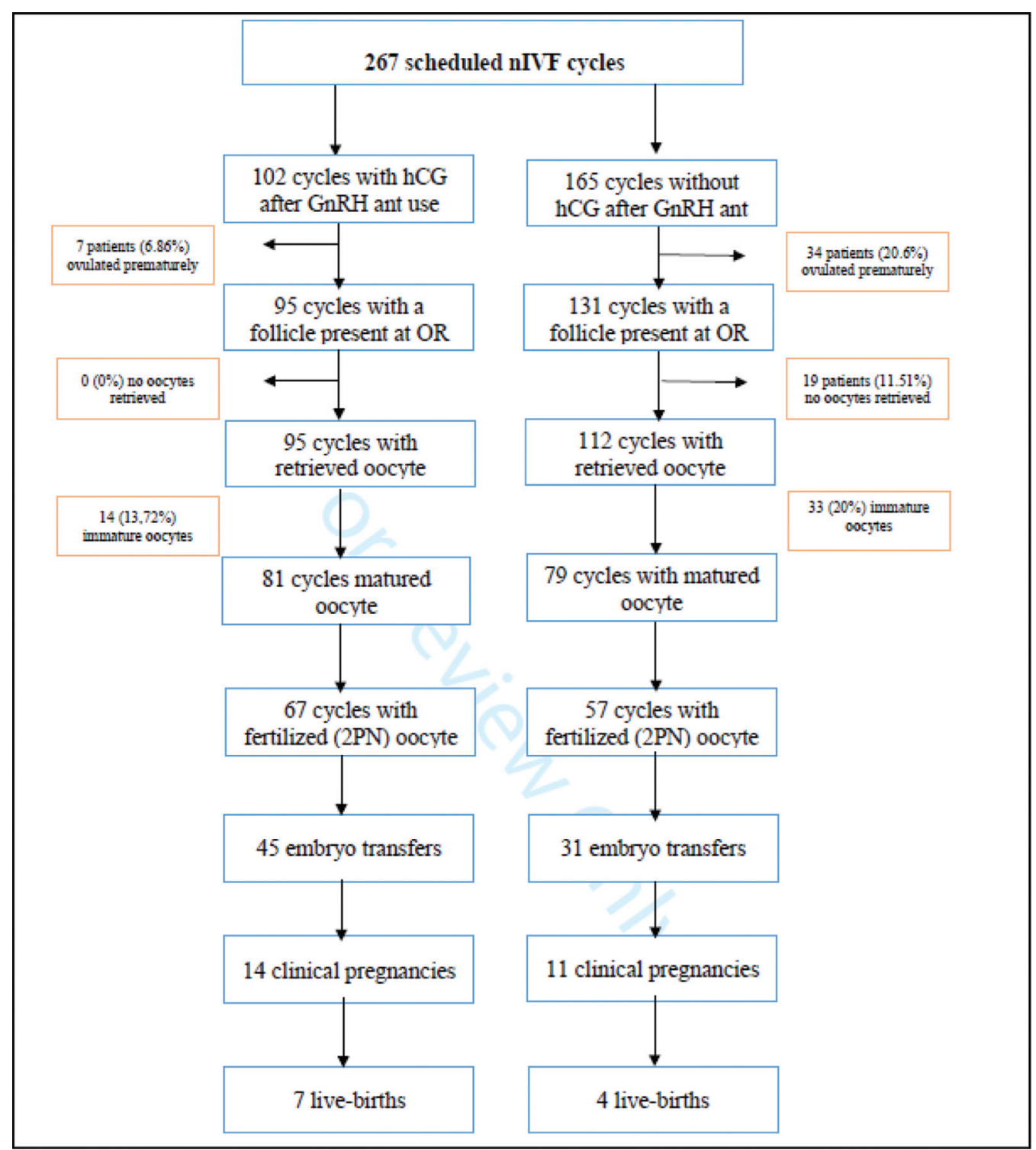

Fig. 1 Consort flow diagram.

ovulation triggering. This LH increase ends with cycle cancellation or premature ovulation, both of which are very frustrating for the patients as well as for the clinicians. There is a higher cancellation rate because of premature LH increase in diminished ovarian reserve patients compared with patients with normal ovarian reserve. The risk factors for this premature luteinization in diminished ovarian reserve patients are not still clearly defined. ${ }^{7,8}$ The aim of GnRH antagonist administration during the controlled ovarian stimulation cycles is to decrease this LH surge before the ovulation triggering. Luteinizing hormone is essential for the follicular growth and final maturation and ovulation of the oocyte. ${ }^{9}$ Luteinizing hormone causes the increase in the androgen secretion from theca cells and, thus, increases the estradiol concentration of the follicle. ${ }^{10}$ Luteinizing hormone in late follicular phase helps the production of small amounts of progesterone, which also triggers follicular growth and maturation enhancing positive estrogen feedback. ${ }^{11}$ Many studies showed the importance of LH levels on follicular growth and concomitant clinical results during controlled ovarian stimulation. ${ }^{12,13}$ Fluctuations of LH levels during late follicular phase have an important role on functional and morphologic changes of the oocytes. It also influences the meiotic and fertilization potential of the oocytes. ${ }^{14}$ The GnRH antagonist protocols have been used commonly in the last years for IVF treatments. ${ }^{15}$ This agent binds to GnRH receptors in the pituitary gland, thus effectively inhibiting LH secretion, and this is how they block premature luteinization and ovulation in IVF cycles. ${ }^{16}$

In addition to a significant decrease in early premature ovulation in the case group for whom we aimed to decrease the premature ovulation risk, a significant increase was also detected in the number of the collected oocytes, mature oocytes, and in the fertilized (2PN) oocyte rates. The detected embryo transfer rate per scheduled cycle was also higher in the case group. However, these results caused no statistically significant difference regarding the rates of clinical pregnancies and live births. 
Table 1 Comparison of the main characteristics and clinical results of the study and control groups

\begin{tabular}{|c|c|c|c|}
\hline Study Groups & GnRH after hCG Group & Standard therapy group & p-value \\
\hline Scheduled cycles & $102(38.2 \%)$ & $163(61.8 \%)$ & - \\
\hline Patient age (range $30-35$ years old) & $32.9 \pm 1.8$ & $33.6 \pm 0.9$ & $0.7821^{*}$ \\
\hline \multicolumn{4}{|l|}{ On triggering day } \\
\hline LH (IU/mL) (range 10-30) & $4,6 \pm 0.7$ & $4,9 \pm 0.9$ & 0.510 \\
\hline Estradiol (IU/mL) (hCG day) & $178 \pm 58.2$ & $174 \pm 67.3$ & $0.608^{*}$ \\
\hline Time between triggering and OR (h) & $36.0 \pm 0.5$ & $36.0 \pm 0.5$ & $0.998^{*}$ \\
\hline Premature ovulation $^{a}$ & $7(6.86 \%)$ & $34(20.6 \%)$ & $0.022^{* *}$ \\
\hline Retrieved oocytes ${ }^{\mathrm{a}}$ & 95 (93.14\%) & $112(67.87 \%)$ & $0.013^{* *}$ \\
\hline Mature oocytes ${ }^{a}$ & $81(79,42 \%)$ & 79 (47.87\%) & $0.041^{* *}$ \\
\hline Fertilized (2PN) oocytes ${ }^{\mathrm{a}}$ & $67(65,68 \%)$ & $57(34.54 \%)$ & $0.018^{* *}$ \\
\hline Embryo transfers ${ }^{\mathrm{a}, \mathrm{b}}$ & $45(44,11 \%)$ & $31(18.78 \%)$ & $0.003^{* *}$ \\
\hline Clinical pregnancies $^{c}$ & $14(13,72 \%)$ & $11(6.66 \%)$ & $0.058^{* *}$ \\
\hline Live birth ${ }^{\mathrm{a}}$ & $7(6.86 \%)$ & $4(2.42 \%)$ & $0.062^{* *}$ \\
\hline
\end{tabular}

Abbreviations: hCG, human chorionic gonadotropin; LH, luteinizing hormone; OR, oocyte retrieval.

apercentage of scheduled cycles.

bsumming fresh and vitrified/warmed embryo transfers.

'Percentage of embryo transfers.

*Independent $t$-test.

${ }^{* *}$ Chi-squared test.

Patients with diminished ovarian reserve represent the group in whom successful treatment is difficult to accomplish during assisted reproduction techniques due to the limited number of ova and embryos, and with low rates of pregnancy. ${ }^{17}$ Also, it was demonstrated in large scaled studies that the rates of pregnancies and live births were lower in patients from whom $\leq 3$ oocytes were obtained, independent of the treatment protocol and age group. ${ }^{18}$ Similarly, it was found in another study that there was no difference in the rates of live births in different groups aged $>$ and $<40$ years old, and the only factor correlated with the rate of live births was the number of oocytes. ${ }^{19}$ We also aimed to obtain more successful cycles in these patient groups, and to be able to increase the number of collected oocytes.

The major problem that may be encountered in patients who are planned to undergo IVF in a natural cycle is early ovulation. The efficacy of natural-cycle IVF is inhibited due to high rates of cancellations because of premature LH increase and premature ovulation. Pelinck et al. ${ }^{2}$ emphasized that it was difficult to control spontaneous LH increase and undesirable early oocyte ovulation detected during oocyte collection, which is one of the main causes of the high rates of cycle cancellations. Therefore, physicians frequently try to collect oocytes in an early period (between 30 and 32 hours), and this approach results in the collection of high numbers of immature oocytes due to early oocyte collection. ${ }^{2}$ Kolibianakis et al. ${ }^{20}$ evaluated the use of antagonists in the treatment of modified natural-cycle IVF treatment in patients with poor ovarian response. Recombinant $\mathrm{FSH}+\mathrm{GnRH}$ antagonist were simultaneously administered when a follicle with a 14-mm was detected, and hCG was administered when the mean follicle diameter was $\geq 16 \mathrm{~mm}$. Oocytes could not be collected from $32.2 \%$ of the patients, and continuing pregnancy could not be achieved. $^{20}$ Although the oocyte collection time was 36 hours after hCG trigger in the case group, cycle cancellations due to premature ovulation was lower compared with the control group and compared with other studies, and the rates of the collected $\mathrm{M}_{2}$ oocytes was higher in the case group in our study.

Our study consists of patients with infertility problem related to diminished ovarian reserve who were observed with just one antral follicle at the beginning of the controlled ovarian stimulation. This group of patients cannot represent the whole infertile group with diminished ovarian reserve, but this can give some knowledge about this limited group of infertile patients with only one antral follicle. The low number of patients in both the case and control groups makes the other limitation of the present study. We could not find a difference in the pregnancy results in both groups, but this may be because of the low number of contributors. We assume that there will be better pregnancy results after finding more available oocytes for fertilization but cannot prove it with this limited number of patients. For clear evidence of better pregnancy results after addition of GnRH antagonist 24 hours after the ovulation triggering, there is need for more comprehensive studies with a large number of patients.

\section{Conclusion}

The administration of a single-dose GnRH antagonist one day after hCG administration enabled a decrease in the rate of premature ovulation and an increase in the number of embryo transfers in patients with diminished ovarian reserve. 


\section{Contributions}

All authors participated in the concept and design of the present study; in the analysis and interpretation of data; in the draft or revision of the manuscript; and they have approved the manuscript as submitted. All authors are responsible for the reported research.

\section{Conflict of İnterests}

The authors have no conflict of interests to declare.

\section{References}

1 Vaiarelli A, Cimadomo D, Ubaldi N, Rienzi L, Ubaldi FM. What is new in the management of poor ovarian response in IVF? Curr Opin Obstet Gynecol. 2018;30(03):155-162. Doi: 10.1097/ GCO.0000000000000452

2 Pelinck MJ, Hoek A, Simons AH, Heineman MJ. Efficacy of natural cycle IVF: a review of the literature. Hum Reprod Update. 2002;8 (02):129-139. Doi: 10.1093/humupd/8.2.129

3 Fluker M, Grifo J, Leader A, Levy M, Meldrum D, Muasher SJ, et al; North American Ganirelix Study Group. Efficacy and safety of ganirelix acetate versus leuprolide acetate in women undergoing controlled ovarian hyperstimulation. Fertil Steril. 2001;75(01): 38-45. Doi: 10.1016/s0015-0282(00)01638-1

4 Al-Inany HG, Youssef MA, Ayeleke RO, Brown J, Lam WS, Broekmans FJ. Gonadotrophin-releasing hormone antagonists for assisted reproductive technology. Cochrane Database Syst Rev. 2016:4-25

5 Borm G, Mannaerts B. Treatment with the gonadotrophin-releasing hormone antagonist ganirelix in women undergoing ovarian stimulation with recombinant follicle stimulating hormone is effective, safe and convenient: results of a controlled, randomized, multicentre trial. The European Orgalutran Study Group. Hum Reprod. 2000;15(07):1490-1498

6 Schoolcraft WB, Surrey ES, Minjarez DA, Stevens JM, Gardner DK. Management of poor responders: can outcomes be improved with a novel gonadotropin-releasing hormone antagonist/letrozole protocol? Fertil Steril. 2008;89(01):151-156. Doi: 10.1016/j. fertnstert.2007.02.013

7 Reichman DE, Zakarin L, Chao K, Meyer L, Davis OK, Rosenwaks Z. Diminished ovarian reserve is the predominant risk factor for gonadotropin-releasing hormone antagonist failure resulting in breakthrough luteinizing hormone surges in in vitro fertilization cycles. Fertil Steril. 2014;102(01):99-102. Doi: 10.1016/j.fertnstert.2014.04.010

8 Messinis IE, Vanakara P, Zavos A, Verikouki C, Georgoulias P, Dafopoulos K. Failure of the GnRH antagonist ganirelix to block the positive feedback effect of exogenous estrogen in normal women. Fertil Steril. 2010;94(04):1554-1556. Doi: 10.1016/j. fertnstert.2009.12.055

9 Balasch J, Miró F, Burzaco I, Casamitjana R, Civico S, Ballescá JL, et al. The role of luteinizing hormone in human follicle development and oocyte fertility: evidence from in-vitro fertilization in a woman with long-standing hypogonadotrophic hypogonadism and using recombinant human follicle stimulating hormone. Hum Reprod. 1995;10(07):1678-1683. Doi: 10.1093/oxfordjournals. humrep.a136154

10 Thelmo MC, Acacio BD, Nouriani M. Peak serum estradiol (E2) is a predictor of pregnancy outcome in vitro fertilization (IVF). Fertil Steril (Poster Presentation Assisted Reproductive Technology). 2006;86:(3, Suppl):187

11 Hattori K, Orisaka M, Fukuda S, Tajima K, Yamazaki Y, Mitzutani T, et al. Luteinizing hormone facilitates antral follicular maturation and survival via thecal paracrine signaling in cattle. Endocrinology. 2018;159(06):2337-2347. Doi: 10.1210/en.2018-00123

12 Gizzo S, Andrisani A, Noventa M, Manfè S, Oliva A, Gangemi M, et al. Recombinant LH supplementation during IVF cycles with a GnRH-antagonist in estimated poor responders: A cross-matched pilot investigation of the optimal daily dose and timing. Mol Med Rep. 2015;12(03):4219-4229. Doi: 10.3892/mmr.2015.3904

13 Wong PC, Qiao J, Ho C, Ramaraju GA, Wiweko B, Takehara Y, et al; Asia Pacific Fertility Advisory Group. Current opinion on use of luteinizing hormone supplementation in assisted reproduction therapy: an Asian perspective. Reprod Biomed Online. 2011;23 (01):81-90. Doi: 10.1016/j.rbmo.2011.03.023

14 Raju GA, Chavan R, Deenadayal M, Gunasheela D, Gutgutia R, Haripriya $G$, et al. Luteinizing hormone and follicle stimulating hormone synergy: A review of role in controlled ovarian hyperstimulation. J Hum Reprod Sci. 2013;6(04):227-234. Doi: 10.4103/0974-1208.126285

15 Ferrero S, Abbamonte LH, Privamera MR, Levi S, Venturini PL, Anserini P. Flexible GnRH antagonist protocol versus GnRH agonist long protocol in patients at high risk of ovarian hyperstimulation syndrome: a prospective randomized controlled trial. Fertil Steril. 2010;94(4, Suppl)S28

16 Depalo R, Trerotoli P, Chincoli A, Vacca MP, Lamanna G, Cicinelli E. Endogenous luteinizing hormone concentration and IVF outcome during ovarian stimulation in fixed versus flexible GnRH antagonist protocols: An RCT. Int J Reprod Biomed. 2018;16(03): 175-182

17 Tarlatzis BC, Zepiridis L, Grimbizis G, Bontis J. Clinical management of low ovarian response to stimulation for IVF: a systematic review. Hum Reprod Update. 2003;9(01):61-76. Doi: 10.1093/ humupd/dmg007

18 El-Toukhy T, Khalaf Y, Hart R, Taylor A, Braude P. Young age does not protect against the adverse effects of reduced ovarian reserve-an eight year study. Hum Reprod. 2002;17(06):1519-1524. Doi: 10.1093/humrep/17.6.1519

19 Polyzos NP, Nwoye M, Corona R, Blockeel C, Stoop D, Haentjens P, et al. Live birth rates in Bologna poor responders treated with ovarian stimulation for IVF/ICSI. Reprod Biomed Online. 2014;28 (04):469-474. Doi: 10.1016/j.rbmo.2013.11.010

20 Kolibianakis E, Zikopoulos K, Camus M, Tournaye H, Van Steirteghem A, Devroey P. Modified natural cycle for IVF does not offer a realistic chance of parenthood in poor responders with high day 3 FSH levels, as a last resort prior to oocyte donation. Hum Reprod. 2004;19(11):2545-2549. Doi: 10.1093/humrep/deh452 